\title{
The growth characteristics of Juniperus excelsa $M$. Bieb. in the greenhouse conditions of the Southern coast of the Crimea
}

\author{
Andrey Pashtetsky ${ }^{1, *}$, Yuri Plugatar ${ }^{1}$, and Oleg Ilnitsky ${ }^{1}$ \\ ${ }^{1}$ Federal State Funded Institution of Science "The Labour Red Banner Order Nikitsky Botanical \\ Gardens - National Scientific Center of the RAS”, Nikita, Yalta, 298648, Russia.
}

\begin{abstract}
The dependence of the growth intensity of Juniperus excelsa $\mathrm{M}$. Bieb on some environmental factors in the greenhouse conditions of the Southern Coast of the Crimea was studied. Vegetation and trunk diameter growth $(\mathrm{d}, \%)$ started after March 15 . There are two growth peaks: the first growth peak (15.03.-27.07.) led to an increase in d,\% by $7.12 \%(0.053 \%$ per day) - with a slowdown in growth (28.04 -27.05) and (13.07-25.07) associated with a decrease in air temperature. The second - $(12.09-18.11)$ led to an increase in $\mathrm{d}, \%$ by $5.06 \%(0.075 \%$ per day $)$, while also slowing growth at this time (05.11.-14.11.) was observed. After the second phase of active growth (14.11), there is an access to the growth plateau with the resumption of the growing season only in March next year. During the studied vegetation period (2019), the increase in trunk diameter $\mathrm{d}, \%$ was $12.18 \%$ or $1.89 \mathrm{~mm}$. Optimal conditions of maxima and boundaries of optimal regions for the first growth peak: $\mathrm{d} \%=\mathrm{f}(\mathrm{I}, \mathrm{Ta})-\mathrm{Ta}=22-28^{\circ} \mathrm{C}$, $\mathrm{I}=500-800 \mathrm{mkmol} / \mathrm{m}^{2} \mathrm{~s}$, for $\mathrm{d}, \%=\mathrm{f}(\mathrm{I}, \mathrm{Da})-\mathrm{Da}=1.8-2.3 \mathrm{kPa}, \mathrm{I}=500-800$ $\mathrm{mkmol} / \mathrm{m}^{2} \mathrm{~s}$. For the second growth peak: $\mathrm{d} \%=\mathrm{f}(\mathrm{I}, \mathrm{Ta})-\mathrm{Ta}=22-26^{\circ} \mathrm{C}$, $\mathrm{I}=400-750 \mathrm{mkmol} / \mathrm{m}^{2} \mathrm{~s}$, for $\mathrm{d}, \%=\mathrm{f}(\mathrm{I}, \mathrm{Da})-\mathrm{Da}=0.3-1.2 \mathrm{kPa}, \mathrm{I}=400-750$ $\mathrm{mkmol} / \mathrm{m}^{2} \mathrm{~s}$.
\end{abstract}

\section{Introduction}

In the conditions of increasing aridization of the territory of the Southern Coast of the Crimea (SCC) and in connection with global climate change $[1,2]$ the study of ecological and physiological features of rare and protected species is a necessary basis for their preservation, development of an environmentally valid system of protection and maintenance of bioecological potential. One of these species is the high juniper (Juniperus excelsa M. Bieb.). There are known works on the conditions of growth of this species in the conditions of the SCC in which the structure of phytocenoses of the Junipereta excelsae formation in the Mountainous Crimea is shown [3].

In the Mediterranean, where this species grows, studies have been conducted to determine environmental characteristics and their seasonal variability [4], as well as to model the dynamics of forests of the Taurus - Turkey mountains [5]. Studies were

\footnotetext{
* Corresponding author: a.v.pashtetskii@gmail.com
} 
conducted to determine the habitat of Juniperus excelsa in southwestern Anatolia (Turkey) along the gradient between the Mediterranean and continental climate [6-8].

Features of the water regime in introduced species allow us to determine the degree of adaptation of plants to environmental conditions [9].

The objective of the work was to study the dependencies of the growth intensity of Juniperus excelsa M. Bieb. on the main environmental factors during the plant vegetation, which allows us to determine the optimal and limiting conditions for the growth of this species in the greenhouse conditions of the SCC.

\section{Materials and methods}

High juniper - Juniperus excelsa M. Bieb. - in the Crimea grows from Cape Aya to Karadag, as well as in the Baydar valley. J. excelsa is an evergreen coniferous tree or shrub 10-15 m high and it grows in the lower mountain belts to a height of $400 \mathrm{~m}$ above sea level on sunny dry slopes, especially on calcite soils. The reproductive cycle (from the laying of cones to the maturation of seeds) in the Crimea is 27 months. Dusting occurs from midJanuary to April [3].

The research was conducted in greenhouses on the territory of the Central Department of the Nikitsky Botanical Gardens. Plants-seedlings 3-4 years old were grown from cuttings. The time of the experiments is 2017-2019. In the course of research to find the relationships between the main weather factors and the growth of the trunk, plants were irrigated to the soil humidity of $80-90 \%$ of minimum moisture-holding capacity.

To measure the characteristics of the environment, a wireless phytomonitoring system was used, which includes PM-11z phytomonitor of "Bioinstruments S.R.L.", a USB adapter and a set of wireless sensors: DWS-11z weather station - a measuring complex that combines a pyranometer (Apogee Instruments, USA), a temperature and humidity sensor, a rain gauge (Decagon Devices, USA) and an anemometer (Davis Instruments (USA). Changes in the diameter of the trunk (shoot) were carried out by dendrometers [10] - FI-Sz, SD-10z sensors, connected to the wireless system of the PM-11z Phytomonitor. [11] Statistical data processing was performed using the application computer programs Statistica 10 ("Statsoft Inc.", USA) and Microsoft Excel 2010. Least squares and robust locally weighted regression (Statistica 10) methods are used for modeling and smoothing two-dimensional data. All calculations were performed at a given significance level $\mathrm{P} \leq 0.05$.

\section{Results}

Study of dependencies of growth intensity of Juniperus excelsa M. Bieb. depending on the main environmental factors in the vegetation process, can determine the optimal and limiting conditions for the growth of this species in the greenhouse conditions of the SCC.

The growth of a trunk is an integral indicator that characterizes the physiological state of the plant and the relationship of its life processes with the main environmental factors [12-15]. Changes in the trunk diameter were measured relative to its value at the beginning of the experiment (basic value) in relative $(\%)$ or absolute $(\mathrm{mm})$ units. The diameter of the trunk of Juniperus excelsa M. Bieb. at the beginning of the experiment, it was $13.38 \mathrm{~mm}$. (basic value). To determine the growth of trunk diameter in different vegetation periods of the species - before the growing season, growth phase and the end of the growing season, a series of studies under greenhouse conditions was conducted. The research results for 2019 are shown below. These periods are characterized by different intensity of weather factors air temperature, solar radiation, and lack of air humidity $[16,9]$. 
Figure 1 shows the dynamics of growth intensity of the trunk of Juniperus excelsa M. Bieb. $(\mathrm{d}, \%)$ and the trend line for 2019.

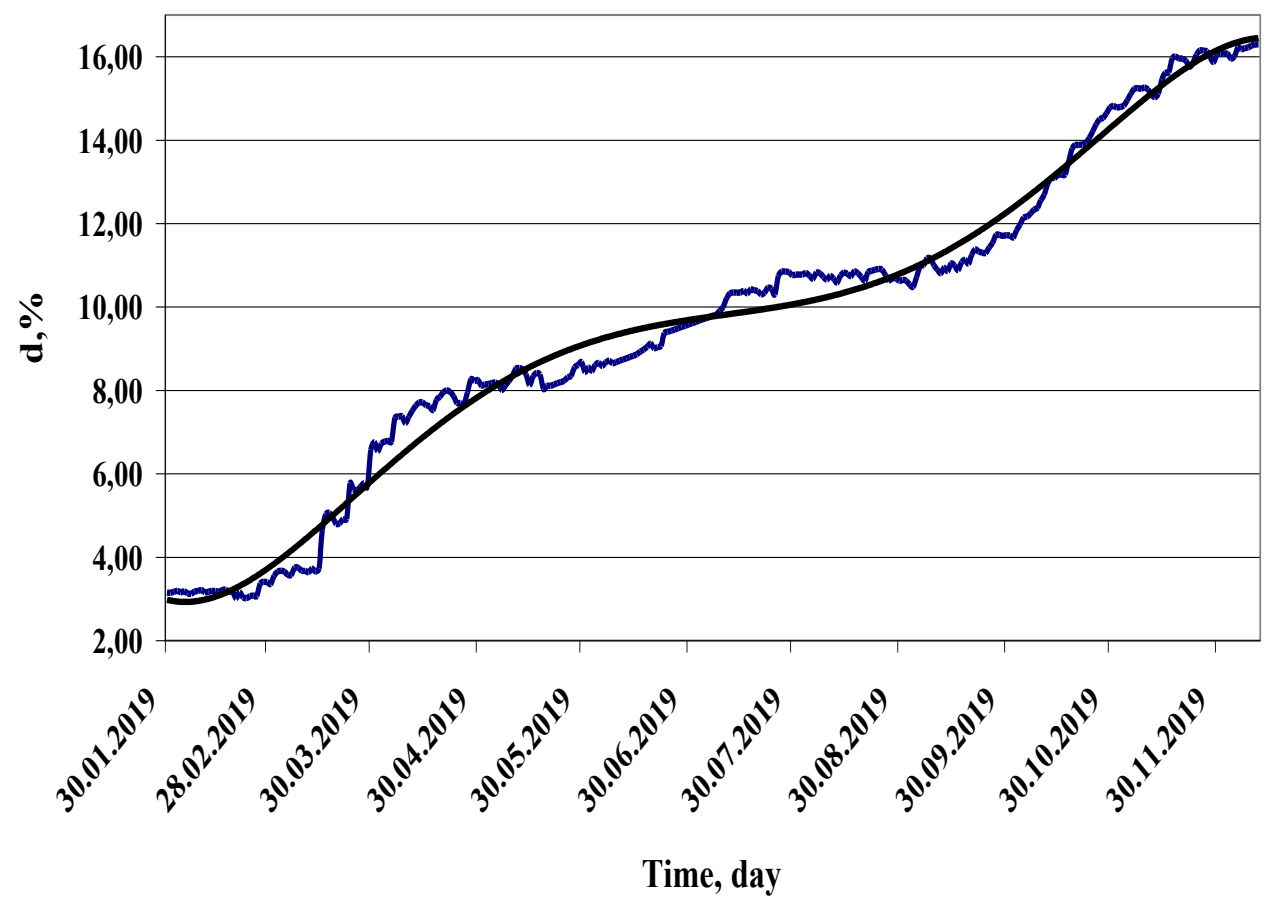

Fig. 1. Dynamics of trunk growth rate (d,\%) Juniperus excelsa M. Bieb - 2019.

Throughout the year there are several phases of vegetation of the species - before the growing season $(31.01-15.03)$, the first phase of active growth $(15.03-27.07)$, access to the plateau growth $(27.07-12.09)$, the second phase of active growth $(12.09-18.11)$ with access to the plateau of cessation of growth.

The first phase of active growth (15.03 - 27.07) of Juniperus excelsa M. Bieb. lasted for 135 days, the increase in the trunk diameter $(\mathrm{d}, \%)$ during this time was $7.12 \%$ of the base value $-0.053 \%$ per day. There is a slowdown in the intensity of growth from 28.04 . 27.05. and from 13.07. - 25.07., associated with a decrease in air temperature. After the first phase of active growth (27.07.), there is an access to the plateau - till 12.09., which is associated with an increase in air temperature to $28-32^{\circ} \mathrm{C}$.

The second peak of active growth lasted 67 days from 12.09. to 18.11. During this period, the increase in the trunk diameter $(\mathrm{d}, \%)$ was $5.06 \%$ of the base value. The average daily increase was $0.075 \%$ per day. The diagram (Fig. 1) shows a slowdown in the growth rate from 05.11. to 14.11., which is associated with a decrease in air temperature. After the second phase of active growth (14.11.) - the reaching the plateau and the vegetation period is resumed only in March next year.

The average daily air temperature throughout the year (Fig.2) also has several peaks: June - July and July - August. 


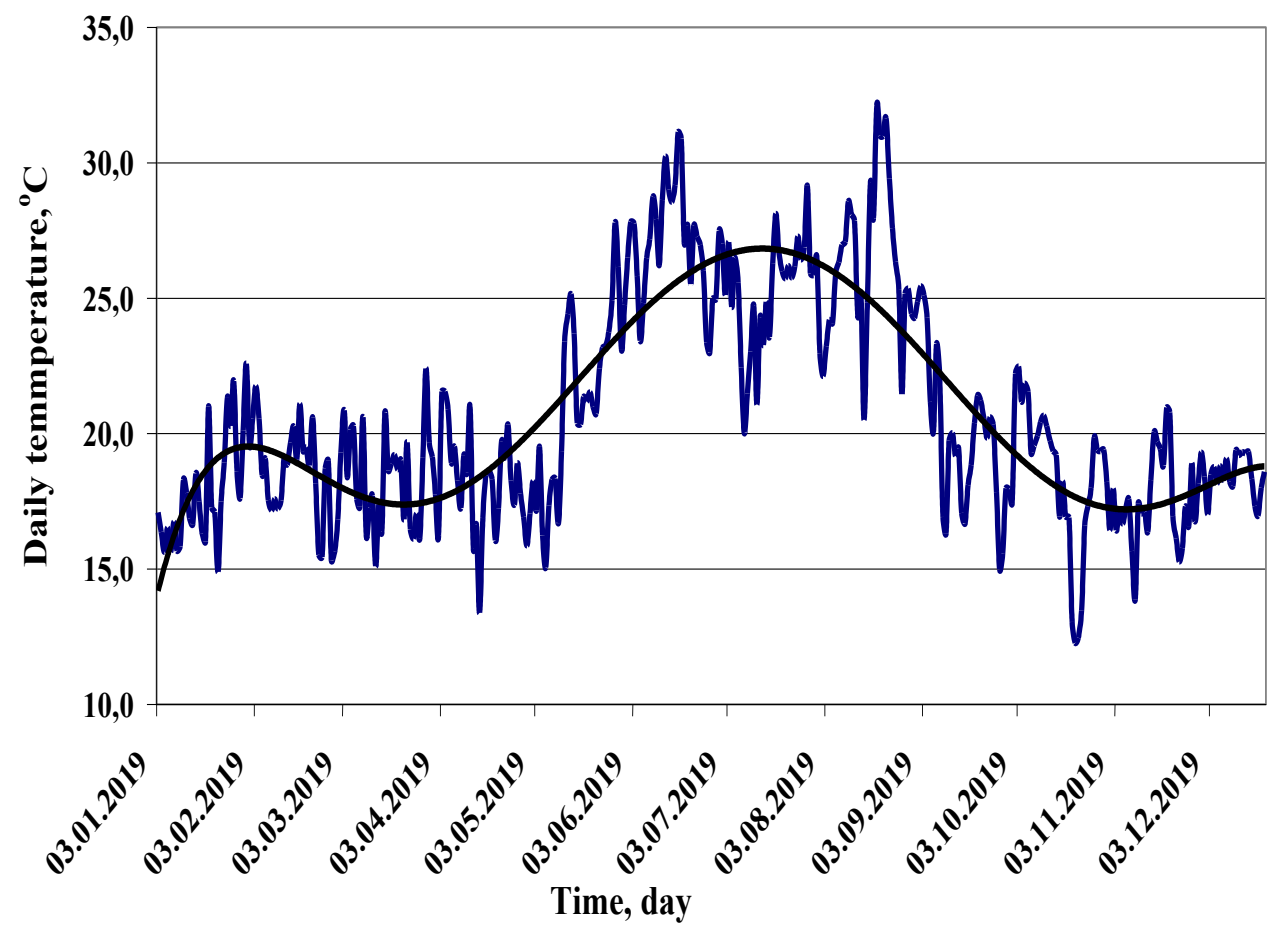

Fig. 2. Dynamics daily temperature air $\left({ }^{\circ} \mathrm{C}\right)$ and trend line -2019 .

The intensity of growth is a function of the response to the impact of the studied environmental factors. This "optimum zone" includes points with a growth intensity value of more than $90 \%$ of $\mathrm{d}$ max, which allowed us to determine the optimal and limiting conditions for maxima and the boundaries of the growth optima regions and the numerical coefficients of nonlinear regression equations of these dependencies [16-17].

Fig. 3 shows the relationship between the intensity of growth of stem of the species under study and the external environment parameters - air temperature and the air humidity deficit in the first phase of active growth - 15.03. - 27.07.

The dependence of the growth rate of total solar radiation and air temperature $\mathrm{d} \%=\mathrm{f}(\mathrm{I}$, $\mathrm{Ta})$ and the linear regression equation of these dependencies. Optimal conditions of maxima and boundaries of the optimum regions- $\mathrm{Ta}=22-28^{\circ} \mathrm{C}, \mathrm{I}=500-800 \mu \mathrm{mol} / \mathrm{m}^{2} \mathrm{~s}$ (Fig. 3A).

The dependence of the growth intensity on the total solar radiation and air humidity deficit $-\mathrm{d}, \%=\mathrm{f}(\mathrm{I}, \mathrm{Da})$ is determined and the equation of nonlinear regression of these dependencies is given (Fig. 3B). Optimal and limiting conditions for maxima and boundaries of the growth optima regions are found, as well as numerical coefficients of nonlinear regression equations of these dependencies-Da=1.8-2.3 $\mathrm{kPa}, \quad \mathrm{I}=500-800$ $\mu \mathrm{mol} / \mathrm{m}^{2} \mathrm{~s}$. 


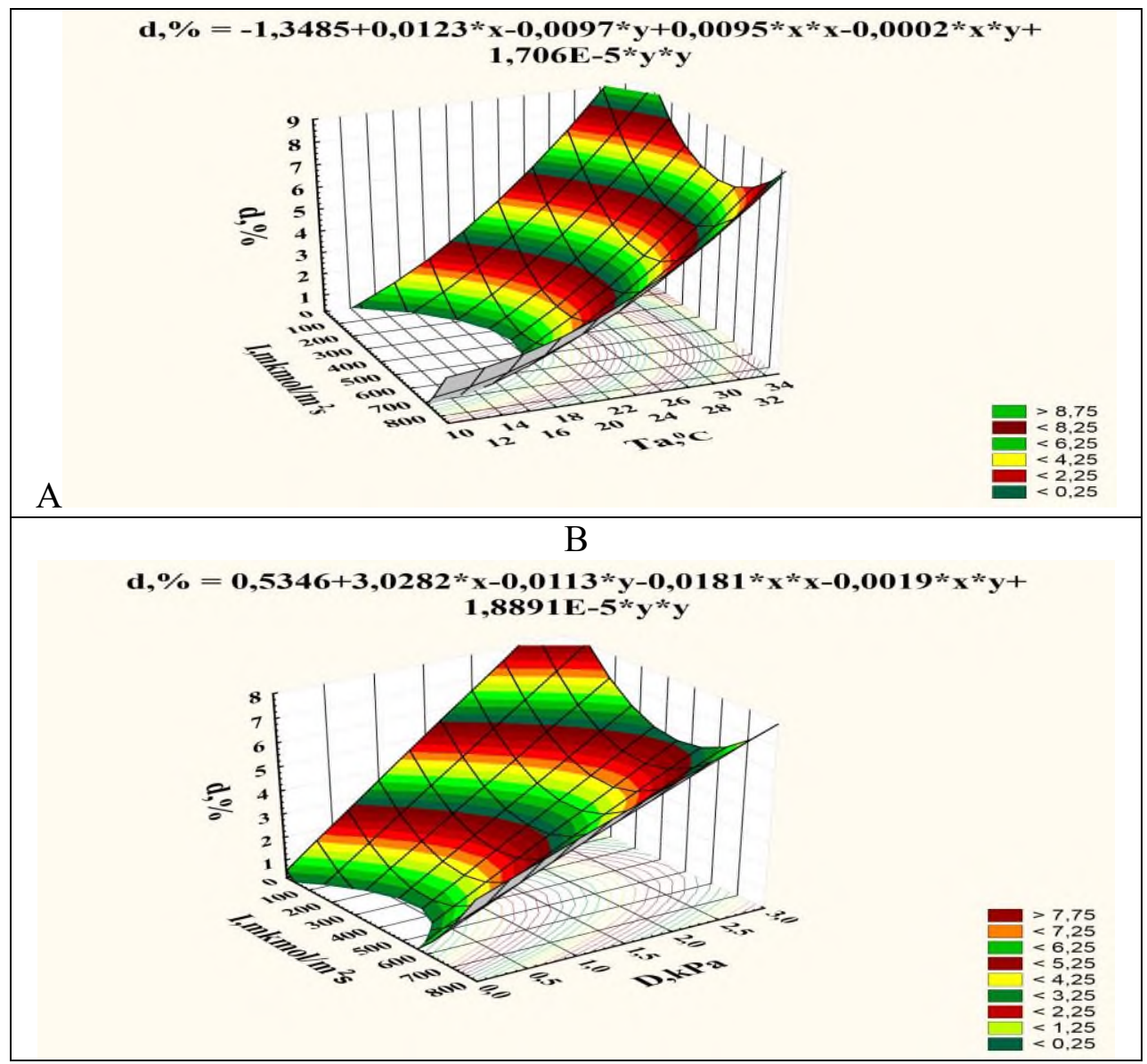

Fig. 3. The dynamics of the intensity of the growth of trunk of Juniperus excelsa M. Bieb. and the relationship of this process with environmental factors in the first phase of active growth - (15.03 27.07) $-\mathrm{A}-$ is the surface of a quadratic function $\mathrm{d}, \%=\mathrm{f}(\mathrm{I}, \mathrm{Ta}) ; \mathrm{B}-\mathrm{d}, \%=\mathrm{f}(\mathrm{I}, \mathrm{Da})$; the numerical coefficients of nonlinear regression equations of these dependencies are shown at the top of the graph.

Fig. 4 shows the relationship between the growth rate of the trunk of the studied species and environmental parameters - air temperature and humidity deficit during the second period of active growth (12.09 - 18.11) of Juniperus excelsa.

The dependence of the growth intensity on the total solar radiation and air temperature is determined-d, $\%=f(I, T a)$ and the equation of nonlinear regression of these dependencies is given (Fig. 4.A). This allowed us to determine the optimal and limiting conditions of maxima and the boundaries of the optimal growth areas - $\mathrm{Ta}=22-26^{\circ} \mathrm{C}, \mathrm{I}=400-750$ $\mu \mathrm{mol} / \mathrm{m}^{2} \mathrm{~s}$.

The dependence of growth intensity on total solar radiation and air humidity deficit $\mathrm{d}, \%=\mathrm{f}(\mathrm{I}, \mathrm{Da})$ is studied and the equation of nonlinear regression of these dependencies is given (Fig. 4B). This allowed us to determine the optimal and limiting conditions of maxima: $\mathrm{Da}=0.3-1.2 \mathrm{kPa}, \mathrm{I}=400-750 \mu \mathrm{mol} / \mathrm{m}^{2} \mathrm{~s}$. 


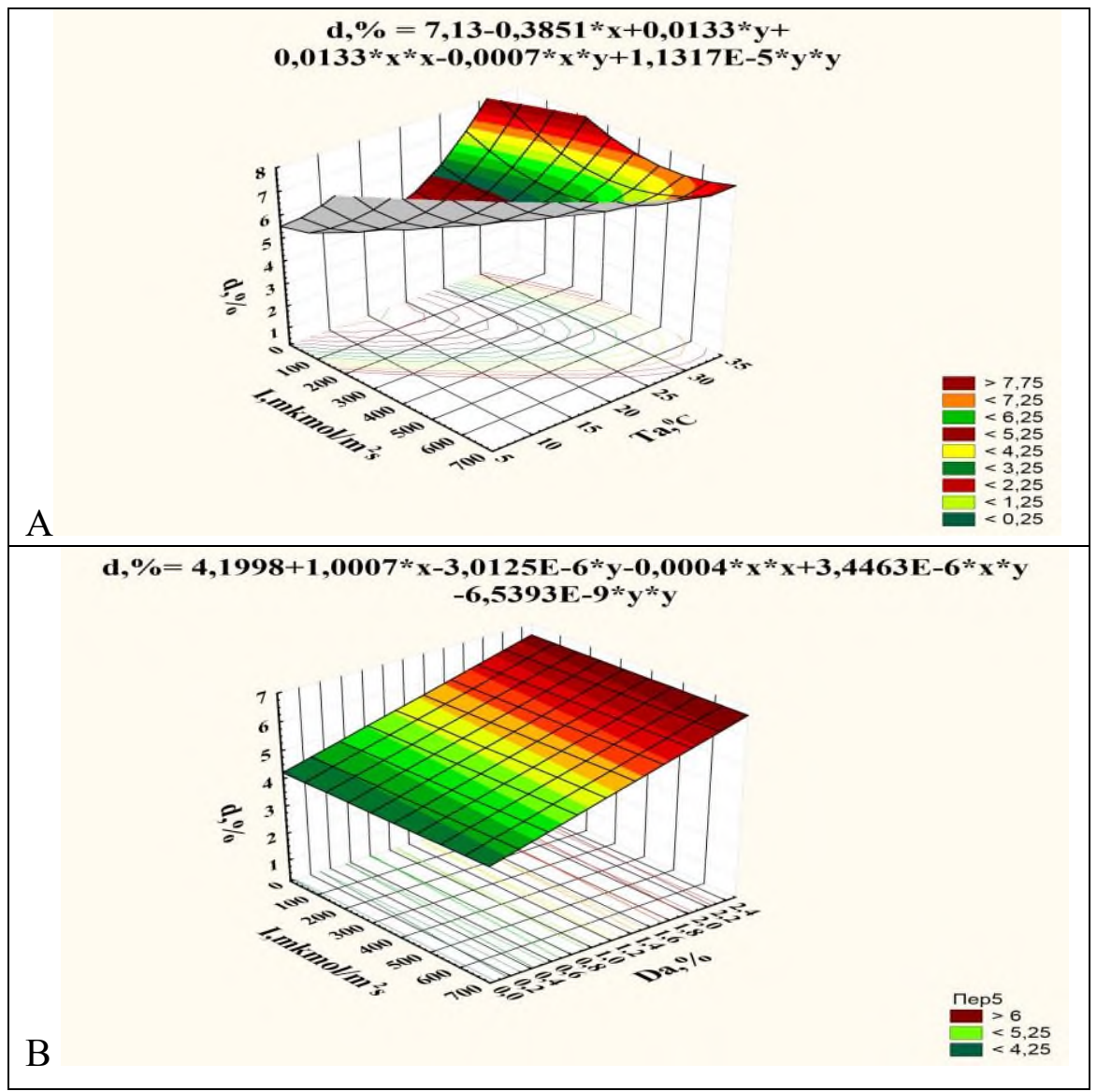

Fig. 4. The dynamics of the intensity of the growth of trunk of Juniperus excelsa M. Bieb. and the relationship of this process with environmental factors in the first phase of active growth - (12.0918.11). A - is the surface of a quadratic function $\mathrm{d}, \%=f(I, T a)) ; B-d, \%=f(I, D a)$; the numerical coefficients of nonlinear regression equations of these dependencies are shown at the top of the graph.

The table 1 shows the dynamics of changes in trunk diameter optima and environmental factors during the growing season of Juniperus excelsa M. Bieb.

Table 1. The dynamics of the optimum diameter of the trunk temperature and environmental factors during vegetation

\begin{tabular}{|c|c|c|}
\hline \multirow{2}{*}{ Parameter, unit } & \multicolumn{2}{|c|}{ Month of measurement } \\
\cline { 2 - 3 } & March-July & September-November \\
\hline $\mathrm{Ta},{ }^{\circ} \mathrm{C}$ & $22-28$ & $22-26$ \\
\hline $\mathrm{Da}, \mathrm{KPa}$ & $1.8-2.3$ & $0.8-1.2$ \\
\hline $\mathrm{I}, \mu \mathrm{mol} / \mathrm{m}^{2} \mathrm{~s}$ & $500-800$ & $400-750$ \\
\hline $\mathrm{d}, \%$ & 7.12 & 5.06 \\
\hline
\end{tabular}

\section{Discussion of the results}


The research allowed us to determine the growth characteristics of the trunk diameter of Juniperus excelsa M. Bieb. in the greenhouse environment of the Southern Coast of the Crimea.

From 31.01. until 15.03.2019. the growth of the trunk diameter of the studied species $\mathrm{d}, \%$ did not occur - the beginning of vegetation was after March 15.

Two growth peaks of the trunk diameter of the studied species were observed: the first growth peak (15.03 - 27.07) led to an increase in $\mathrm{d}, \%$ by $7.12 \%(0.053 \%$ per day $)$ - at the same time, there was a slowdown in growth (28.04 - 27.05) and (13.07-25.07), associated with a decrease in air temperature. The second growth peak $(12.09-18.11)$ led to an increase in $\mathrm{d}, \%$ by $5.06 \%(0.075 \%$ per day) and then to a slowdown in growth $(05.11-$ 14.11).

After the second phase of active growth (14.11), there is an access to the plateau with the resumption of the growing season only in March next year.

During the studied vegetation period (2019), the increase in trunk diameter $\mathrm{d}, \%$ was $12.18 \%$ or

$1.899 \mathrm{~mm}$.

Optimal conditions of maxima and boundaries of optimal regions for the first growth peak $-\mathrm{d} \%=\mathrm{f}(\mathrm{I}, \mathrm{TV})-\mathrm{Ta}=22-28^{\circ} \mathrm{C}, \mathrm{I}=500-800 \mu \mathrm{mol} / \mathrm{m}^{2} \mathrm{~s},-\mathrm{d}, \%=\mathrm{f}(\mathrm{I}, \mathrm{Da})-\mathrm{Da}=1.8-2.3$ $\mathrm{kPa}, \mathrm{I}=500-800 \mu \mathrm{mol} / \mathrm{m}^{2} \mathrm{~s}$.

For the second peak of the growth $\mathrm{d} \%=\mathrm{f}(\mathrm{I}, \mathrm{Ta})-\mathrm{Ta}=22-26^{\circ} \mathrm{C}, \mathrm{I}=400-750 \mu \mathrm{mol} / \mathrm{m}^{2} \mathrm{~s}$, $\mathrm{d}, \%=\mathrm{f}(\mathrm{I}, \mathrm{DV}) \mathrm{Da}=0.3-1.2 \mathrm{kPa}, \mathrm{I}=400-750 \mu \mathrm{mol} / \mathrm{m}^{2} \mathrm{~s}$.

The obtained research results allowed us to determine the optimal and limiting conditions for the growth of this species in the greenhouse conditions of the SCC and the possibility of its introduction to other regions.

\section{References}

1. F. Giorgi, P. Lionello, Climate change projections for the Mediterranean region. Glob Planet Change, 63, 90-104 (2008) doi:10.1016/j.gloplacha.2007.09.005

2. S. S. Fatemi, M. Rahimi, M Tarkesh., H. Ravanbakhsh, Predicting the impacts of climate change on the distribution of Juniperus excelsa M. Bieb. in the central and eastern Alborz Mountains, Iran. iForest, 11, 643-650 (2018) doi: 10.3832/ifor2559-011

3. A. V. Jena, A. V. Feteria, Red book of the Republic of Crimea. Plants, algae, fungi. Exec. Editor Simferopol: LLC IT «ARIAL», 480 (2015)

4. D. Sperlich, C. T. Chang, J. Peñuelas, C. Gracia, S. Sabaté, Seasonal variability of foliar photosynthetic and morphological traits and drought impacts in a Mediterranean mixed forest. Tree Physiology, 35, 501-520 (2015) doi:10.1093/treephys/tpv017

5. V. Kint, W. Aertsen, N. M. Fyllas, A. Trabucco, E. Janssen, K. Özkan, B. Muys, Ecological traits of Mediterranean tree species as a basis for modelling forest dynamics in the Taurus mountains, Turkey, Ecological Modelling, 286, 53-65 (2014)

6. K. Özkan, S. Gulsoy, R. R. Aerts, B. Muys, Site properties for Crimean juniper (Juniperus excelsa) in semi-natural forests of south western Anatolia, Turkey. J. Environ. Biol. 31, 97-100 (2010)

7. L. C. Jovellar, L. Fernández, M. Mezquita, F. Bolaños, V. Escudero, Structural characterization and analysis of the regeneration of woodlands dominated by Juniperus oxycedrus L. in west-central Spain. Plant Ecol, 214, 61-73 (2013) Cross Ref Google Scholar 
8. C. J. Willson, C. J., P. S. Manos, R. B. Jackson, Hydraulic traits are influenced by phylogenetic history in the drought-resistant, invasive genus Juniperus (Cupressaceae). Am J Bot, 95, 299-314 (2008) Pub Med Cross Ref Google Scholar.

9. C. Mayoral, R. Calama, M. Sa'nchez-Gonza'lez, M. Pardos, Modelling the influence of light, water and temperature on photosynthesis in young trees of mixed Mediterranean forests New Forests, 46, 485-506 (2015) DOI 10.1007/s11056-0159471-y

10. R. Cruz-García, A. Balzano, K. Čufar, T. Scharnweber, M. Smiljanić and M. Wilmking Combining Dendrometer Series and Xylogenesis Imagery-DevX, a Simple Visualization Tool to Explore Plant Secondary Growth Phenology, 2, 60 (2019) Front. For. Glob. Change doi: 10.3389/ffgc.2019.00060

11. O. A. Ilnitsky, Yu. V. Plugatar, S. P. Korsakova, Methodology, instrument base and practice of phytomonitoring. Simferopol: IT “ARIAL”, 236 (2018)

12. S. Gülcü, H. C. Gültekin, S. Çelik, , Y. Eser, N. Gürlevik, The effects of different pot length and growing media on seedling quality of Crimean juniper (Juniperus excelsa Bieb.), African Journal of Biotechnology 2010, 9(14), 2101-2107 (2010) ISSN 16845315

13. N. Gürlevik, A. Deligöz, D. Yıldız, Effects of irrigation and fertilization on the growth of juniper seedlings Der Einfluss von Bewässerung und Düngung auf das Wachstum von Wacholdersämlingen. Austrian Journal of Forest Science Centralblatt fur das gesamte Forstwesen. Jahrgang, 3, 171-190 (2014)

14. E. Karapatzak, G. Varsamis, I. Koutseri, I. Takos, T. Merou, The effect of pollen performance on low seed fertility in a Greek population of Juniperus excelsa. J. For. Sci., 65, 356-367 (2019) doi. org/10.17221/42/2019-JFS

15. M. Öncel, H. Vurdu, 1. Kaymakçı, A, Özkan, E. Osman, H. Aydoğan, COATING PERFORMANCES OF CRIMEAN JUNIPER (Juniperus excelsa M. BIEB.) WOOD. $\begin{array}{lllllll}\text { CERNE, 25(1), } & \text { 36-43 (2019) } & \text { Epub }\end{array}$ https://doi.org/10.1590/01047760201825012599

16. S. N. Drozdov, E. S. Kholoptseva, Possibilities of using a multi-factor experiment in the study of ecological and physiological characteristics of plants. Scientific notes of Petrozavodsk state University, 2(131), 11-15 (2013)

17. R. B. Abdolrahman, S. Hassan, R. P. Hamid, T. Blaschke, Predicting Habitat Suitability and Conserving Juniperus spp. Habitat Using SVM and Maximum Entropy Machine Learning Techniques Department of Horticulture Science, College of Agriculture, Shiraz University, 11(10), Shiraz 71441-65186 (2019) https://doi.org/10.3390/w11102049 